\title{
Impact of the COVID-19 pandemic on appendicitis treatment in Germany-a population-based analysis
}

\author{
Franziska Köhler ${ }^{1}$ - Laura Acar ${ }^{2}$ - Anne van den Berg ${ }^{1}$. Sven Flemming ${ }^{1} \cdot$ Carolin Kastner $^{1,3} \cdot$ Sophie Müller ${ }^{1}$. \\ Johannes Diers ${ }^{1} \cdot$ Christoph-Thomas Germer ${ }^{1,4}$ • Johann F. Lock ${ }^{1} \cdot$ Helmut L'hoest ${ }^{2}$. Ursula Marschall ${ }^{2}$. \\ Armin Wiegering ${ }^{1,3,4}$ (B)
}

Received: 13 October 2020 / Accepted: 4 January 2021

(C) The Author(s), under exclusive licence to Springer-Verlag GmbH, DE part of Springer Nature 2021

\begin{abstract}
Purpose Acute appendicitis is one of the most common reasons for emergency medical consultation. While simple appendicitis can be treated with antibiotics or surgery, complex appendicitis including gangrene, abscess, and perforation requires appendectomy. During the COVID-19 pandemic in early 2020, an overall drop in emergency room consultations was observed. We therefore aimed to investigate the incidence and treatment strategies of acute appendicitis during that period.

Methods Data of insurance holders with the ICD code for "acute appendicitis" or OPS procedure of appendectomy of a major health insurance company in Germany were analyzed retrospectively. Groups were built, containing of the means of March-June of 2017, 2018, and 2019, defined as "pre-COVID group" with the "COVID group," defined as data from March to June of 2020. Data was analyzed by age, sex, comorbidities, length of hospital stay, diagnoses, and treatment. Data of the COVID group was analyzed for simultaneous COVID-19 infection.

Results During the COVID-19 pandemic of early 2020, an overall reduction by $12.9 \%$ of patients presenting with acute appendicitis was noticeable. These results were mainly due to decreased rates of uncomplicated appendicitis, while complicated appendicitis was scarcely affected. Especially in the group of females $<40$ years, a drastic reduction was visible. Rates of extended surgery did not change. Likewise, the complication rate like appendix stump leakage or need for re-operation did not differ. In March 2020, 4.8\% of acute appendicitis patients had concomitant COVID-19 infection.

Conclusion In line with the overall drop of emergency room visits during the COVID-19 pandemic of spring 2020 in Germany, a significantly lowered number of patients with uncomplicated appendicitis were noticeable, whereas complicated appendicitis did not differ. Also, treatment and complication rate of acute appendicitis did not change. These findings might be a hint that acute appendicitis is not a progressing disease but caused by different entities for uncomplicated and complicated appendicitis and therefore another clue that uncomplicated appendicitis can be treated with antibiotics or observation. Nevertheless provided data does not cover outpatient treatment; therefore, no statement observation or antibiotics in outpatients can be made.
\end{abstract}

Keywords Acute appendicitis · Laparoscopic appendectomy · Open appendectomy · COVID-19 · Germany · Complicated appendicitis

Armin Wiegering

Wiegering_A@ukw.de

1 Department of General, Visceral, Transplantation, Vascular and Pediatric Surgery, University Hospital, University of Wuerzburg, Oberduerrbacherstr. 6, 97080 Wuerzburg, Germany

2 BARMER, Wuppertal, Germany

3 Department of Biochemistry and Molecular Biology, University of Wuerzburg, Am Hubland, 97074 Würzburg, Germany

4 Comprehensive Cancer Centre Mainfranken, University of Wuerzburg Medical Centre, Josef-Schneiderstr. 2, 97080 Wuerzburg, Germany

\section{Introduction}

Acute appendicitis (AA) is one of the most common causes of acute abdominal pain in emergency units worldwide [1]. Lifetime risk to develop appendicitis is reported to be approximately $8 \%[1-3]$.

Causes of AA like luminal obstruction, genetic predisposition, or environmental factors are widely discussed $[2,4,5]$. Typical symptoms in patients with AA are pain in the right lower quadrant or central abdominal pain with migration to the right iliac fossa as well as fever, nausea, vomiting, or 
constipation $[1,2,6]$. Imaging techniques, mainly ultrasound, computed tomography, or magnetic resonance imaging, are often used to ensure the diagnosis $[1,2,7]$.

Appendicitis can be divided into phlegmonous, gangrenous, and perforation leading to peritonitis or abscess [2].

For many years, appendicitis was thought to be a progressing disease, but recent data suggest there might be two different entities: first, simple appendicitis (i.e., phlegmonous) which is unlikely to progress to perforation and might be treated with antibiotic therapy or appendectomy and second, complex appendicitis which seems to progress rapidly and therefore is more likely to lead to perforation or abscess. Thus, it should be treated with appendectomy which can be performed traditionally with a small incision in the right lower quadrant or laparoscopically [2]. In some cases, abscess can be treated with percutaneous CT- or ultrasoundguided drainage [8].

In December 2019, rising pneumonia cases of unknown origin were reported in Wuhan, Hubei province, China. Shortly after, the novel RNA betacoronavirus (severe acute respiratory syndrome coronavirus 2 /SARS-CoV-2) was identified to be the cause of these infections, commonly named COVID-19 [9]. First, COVID-19 began to spread throughout China before it became a worldwide infectious disease in early 2020 , marking the begin of a pandemic $[10,11]$.

In Germany, infections started rising in March 2020, reaching 162,333 cases on April 30, 2020 [12]. The German government scheduled a nationwide "lockdown" in midMarch to slow down infections. Kindergarten, schools, and shops other than supermarkets, pharmacies, or drugstores were closed. Meeting friends or family outside the own household, commonly named social distancing, was prohibited. Restrictions were loosened in May 2020, when COVID-19 infection rates started slowing down [13].

To prevent a breakdown of the national health system and provide sufficient medical care for COVID-19 patients as well as others, German hospitals developed strategies to care for both groups of patients to maintain its high quality health care. Schedulable procedures were postponed, and interventions were prioritized to keep up with emergency conditions like acute appendicitis $[13,14]$.

This study aims to investigate the characteristics and treatment of patients with AA in Germany during the COVID-19 pandemic in 2020 compared to a pre-COVID-19 period. Therefore, large-scale population-based health insurance claims data were used.

\section{Methods}

This is a retrospective cohort study, based on anonymized nationwide administrative data provided by "BARMER," an insurance company, that provides health insurance for approximately 9 million German habitants. Thus, BARMER covers about $10 \%$ of the German population. Diagnoses were coded using the 10th revision of the International Classification of Diseases (ICD-10). All performed procedures were coded according to the German version of the International Classification of Procedures in Medicine (ICPM) called "Operationen- und Prozedurenschlüssel" (OPS).

In-house patients with pathologies of the appendix (ICD10: $\mathrm{K} 35^{*}-\mathrm{K} 37^{*}$ ) were included. Incidences were calculated in rates per 1 million insurance holders per month. Procedure codes were graded hierarchically, with more extensive resections counting as main intervention (bowel resection, OPS 5$455.0 * ; 4-455.2 * ; 4-455.3 *$ /open or converted appendectomy, $5-470.0 * ; 5-470.2 * /$ laparoscopic appendectomy, 5-471.1*). In-house patients with ICD-10 codes for appendicitis and missing OPS codes were listed as non-surgical treatment.

Appendicitis was divided into uncomplicated appendicitis (UA) and complex appendicitis (CA). UA was defined as acute appendicitis with at most localized peritonitis (ICD-10: $\mathrm{K} 35.30, \mathrm{~K} 35.8, \mathrm{~K} 36^{*}$, or $\left.\mathrm{K} 37^{*}\right)$. CA was defined as acute appendicitis with perforation, abscess, or generalized peritonitis (K35.2, K35.31, or K35.32).

We defined the reference period ("pre-COVID-19") from March to June of 2017, 2018, and 2019. Comparing the averages of 2017, 2018, and 2019, there was a variation of $\pm 2 \%$; therefore, we calculated the means of March-June 20172019.

"COVID-19 period" or observation period was defined as March-June 2020.

Patient characteristics (age, gender, comorbidities), appendicitis stage, performed procedure, length of hospital stay, and complications were summarized in descriptive statistics.

During the reference period, simultaneous COVID-19 infection was analyzed using the corresponding ICD-10 that was just added in February 2020 (ICD-10 UO7.1).

Differences between reference and observation period were compared using univariate $\chi 2$ or Student's $t$ tests with a significance level of 0.05 . All calculations were performed with the software Microsoft Excel (version 16.36) and GraphPad Prism 8.

\section{Results}

\section{Reference period}

During the reference period (March-June 2017-2019), approximately 13,000 insurance holders developed AA (116 per 1 million insurance holders/month) and in roughly 11,500 (105 per 1 million insurance holders/month) appendectomies were performed (see Table 1). There was a 
Table 1 Patients characteristics during reference and observation period

\begin{tabular}{llll}
\hline & Reference period & Observation period & $p$ value \\
\hline Appendicitis per 1 million insurance holders/month & $116 \pm 8.5$ & $101 \pm 8.9$ & 0.0091 \\
Female (\%) & $56.0 \%$ & $53,6 \%$ & n.s. \\
Appendectomies per 1 million insurance holders/month & $106 \pm 8.0$ & $92 \pm 7.0$ & 0.0077 \\
Age $<40$ & $60.4 \%$ & $58.6 \%$ & n.s. \\
Age 40-60 & 23.3 & 23.7 & \\
Age 60-80 & 13.6 & 14.8 & \\
$>80$ & 2.6 & 2.8 & \\
Average age (in years) & $38.59 \pm 0.9$ & $39.91 \pm 0.4$ & $<0.0001$ \\
At least one comorbidity (\%) & $26.0 \% \pm 1.7$ & $28.8 \% \pm 1.0$ & 0.0082 \\
Obesity (\%) & $5.7 \% \pm 0.8$ & $6.3 \% \pm 0.5$ & n.s. \\
Cardiac disease (\%) & $8.6 \% \pm 1.1$ & $9.6 \% \pm 1.3$ & n.s. \\
Diabetes (\%) & $3.9 \% \pm 1.3$ & $4.5 \% \pm 0.9$ & n.s. \\
Hypertension (\%) & $17.9 \% \pm 1.3$ & $20.1 \% \pm 1.0$ & 0.0083 \\
Chronic kidney disease (\%) & $8.7 \% \pm 1.2$ & $9.7 \% \pm 0.5$ & n.s. \\
\hline
\end{tabular}

variation of $\pm 2 \%$ noticeable each year; we therefore did not itemize each year on its own but counted the averages of 2017-2019.

Cases of COVID-19 increased exponentially in Germany during the observation period, and deaths due to COVID-19 began to rise in mid-April (see Fig. 1).

The average patient age was 38 years, $56 \%$ were female, and $26 \%$ had at least one of COVID-19 risk comorbidities (obesity, cardiac disease, diabetes, hypertension, or chronic renal failure) (see Table 1).

$23.5 \%$ of the patients suffered from complex appendicitis (CA), defined as acute appendicitis with perforation, abscess, or generalized peritonitis (see Table 2).

Ninety-one percent of patients admitted with AA underwent surgical intervention (appendectomy and/or bowel resection). $86.7 \%$ received appendectomy and in $4.3 \%$ merely bowel resection was coded. Ninety-three percent of appendectomies were performed laparoscopically, while $7 \%$ were performed open or converted to open. Of patients treated with

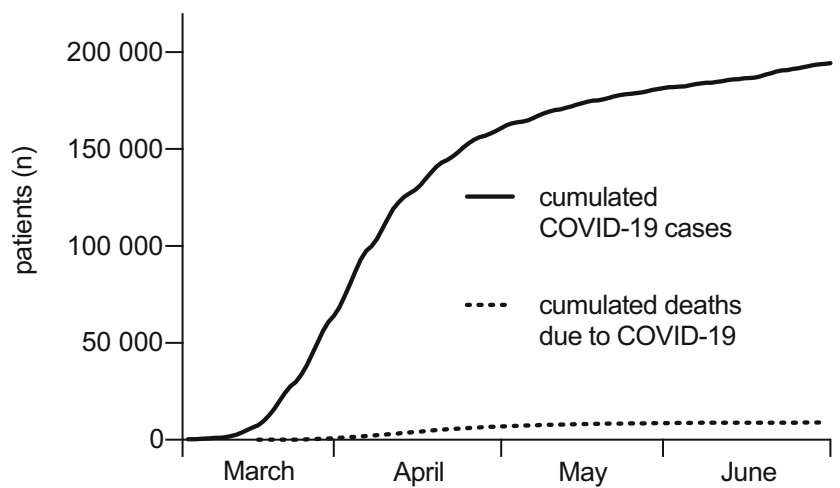

Fig. 1 Cumulated COVID-19 cases and deaths due to COVID-19 from March to June 2020 in Germany appendectomy, $6.1 \%$ needed additional bowel resection (see Table 4).

\section{Observation period}

During the COVID-19 period, the number of appendicitis cases dropped by $12.9 \%$ to $101 / 1$ million insurance holders per month ( $p=0.009$ ) (see Fig. 2 and Table 1). Patients were on average 1 year older, whereas the female to male ratio did not change significantly. Percentage of insurance holders with at least one COVID-19 risk factor increased significantly $(26 \% \pm 1.7$ vs. $28.8 \% \pm 1.0 \% ; p=0.0082)$. For a detailed description of comorbidities, see Table 1.

UA dropped by $16 \%$ during observation period $(89 \pm 7.5$ to $75 \pm 6.8$ per 1 million insurance holders/month; $p=0.0053$ ). In contrast, CA did not change significantly ( $27 \pm 2.0$ vs. $26 \pm$ 2.7; n.s.) as shown in Table 2.

In line with the reduced numbers of UA, the rate of laparoscopic appendectomies ( $94 \pm 7$ vs $82 \pm 7, p=0.01)$ and open or converted appendectomies decreased significantly $(7.1 \pm$ 1.3 vs $5.4 \pm 0.7 ; p=0.027$ ) (see Table 4 ). The rate of nonsurgical treated appendicitis decreased by $16 \%(p=0.06)$.

Numbers of appendicitis patients needing additional bowel resection as a surrogate parameter for a complicated appendicitis did not change $(6.4 \pm 0.5$ vs. $6.4 \pm 1.2$; n.s.) (see Table 4$)$.

The most significant drop was seen in females $<40$ years with an overall decrease of $21.8 \%$; UA was reduced by $23.7 \%$ whereas CA dropped by $5.3 \%$. In comparison to this, in the age group $>40$ years, an overall reduction of only $8.4 \%$ was seen (UA - 9.2\%, CA - 7\%). Interestingly, in the male population $<40$ years, a reduction by $5.5 \%$ was noticeable (UA $8.7 \%$, CA $10.6 \%$ ). In the male age group $>40$ years, an overall drop by $9.9 \%$ was visible. 
Table 2 Classification of appendicitis during reference and observation period

\begin{tabular}{llll}
\hline & $\begin{array}{l}\text { Reference } \\
\text { period }\end{array}$ & $\begin{array}{l}\text { Observation } \\
\text { period }\end{array}$ & $p$ value \\
\hline $\begin{array}{l}\text { Uncomplicated appendicitis per 1 million insurance holders } \\
\text { Complicated appendicitis per 1 million insurance holders }\end{array}$ & $\begin{array}{l}89 \pm 7.5 \\
27 \pm 2.0\end{array}$ & $\begin{array}{l}75 \pm 6.8 \\
26 \pm 2.7\end{array}$ & $\begin{array}{l}0.0053 \\
\text { n.s. }\end{array}$ \\
\hline
\end{tabular}

The mean length of a hospital stay decreased from 4 to 3 days. Rates of patients who were re-admitted within 30 days dropped significantly from $6.8 \pm 0.81$ to $5.8 \% \pm 0.61$. Overall occurrence of postoperative complication was low. There was no difference between reference and observation period regarding anastomosis or appendix stump leakage, the need for re-operation, or septic episodes (see Table 5).

One hundred four patients who were treated for AA were simultaneously diagnosed with COVID-19. The highest rate was seen in April 2020, where $4.8 \%$ of AA patients were tested positive for COVID-19. Of patients with concomitant COVID-19 infection, 39.4\% suffered from complex appendicitis, whereas during reference period only $23.5 \%$ had CA. There was no difference in the treatment of non-COVID and COVID-infected AA patients. Approximately $91.4 \%$ of both groups received surgery. Our data does not provide information about symptoms or severity of the COVID-19 infection (see Tables 3, 4, 5).

\section{Discussion}

This is the largest population-based analysis of appendicitis treatment during the COVID-19 pandemic of spring 2020 in Germany so far. Data from more than 16,000 patients treated for appendicitis divided into pre-COVID19 and COVID-19 groups were included and analyzed. Prevalence of appendicitis in our population matches the nationwide appendectomy prevalence [15]; therefore, it seems likely that BARMER health insurance covers a representative sample of the German population.

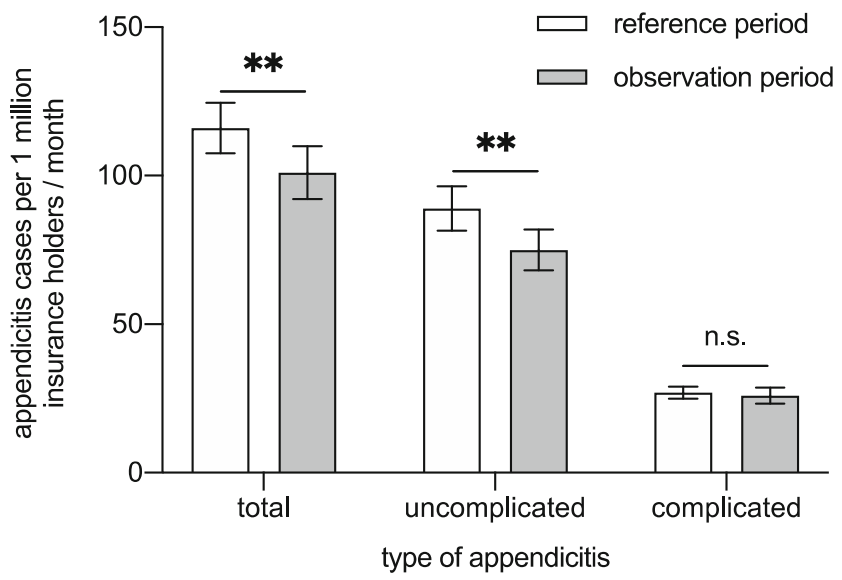

Fig. 2 Types of appendicitis during reference and observation period
When COVID-19 hit Germany in early 2020, a significant reduction in emergency department visits was noticeable, concerning medical but also surgical patients. Reasons for this shift are widely discussed and some might be less trauma patients due to the "stay at home" advice and therefore reduced traffic volume or fear of getting infected with COVID-19 in medical facilities and therefore only seeking medical health for severe conditions [16]. In this analysis, we can confirm the abovementioned trend regarding patients with acute appendicitis, with a significant reduction of overall appendicitis cases visible from March to June 2020, compared to March-June of 2017-2019. The complication rate after appendicitis is generally described at $2.1 \%$ in a 2019 published nationwide analysis [17] and did not rise during COVID-19.

The decrease in UA patients during COVID-19 might support the theory of two different entities for AA and can be a hint to disconfirm the hypothesis of a progressive disease. According to this theory, UA can be treated symptomatically, with antibiotics or by performing appendectomy [2]. Our findings might be evidence that patients with mild symptoms of AA were successfully treated as outpatients or even did not seek medical help at all. However, the given data does not provide information about outpatient treatment. On the other hand, patients with severe symptoms caused by acute appendicitis did not hesitate to seek medical treatment during observation period in spring 2020 .

It is an ongoing debate whether patients with UA are in need of surgical intervention or if antibiotic therapy or even "watch-and-wait" is a safe treatment option. To date, several systematic literature reviews and randomized controlled trials were performed [3, 18-21]. Harnoss et al. stated that appendectomy is a one-time only treatment with a low-risk profile [19] whereas the recently

Table 3 Differentiation of appendicitis and therapeutic regime in COVID and non-COVID patients

\begin{tabular}{lll}
\hline & Non-COVID & COVID infected \\
\hline Complicated appendicitis & $885(95.57 \%)$ & $41(4.43 \%)$ \\
Uncomplicated appendicitis & $2624(97.66 \%)$ & $63(2.34 \%)$ \\
Surgical therapy & $3207(91.39 \%)$ & $95(91.35 \%)$ \\
Conservative therapy & $302(8.61 \%)$ & $9(8.65 \%)$ \\
\hline
\end{tabular}


Table 4 Appendicitis treatment during reference and observation period

\begin{tabular}{llll}
\hline & $\begin{array}{l}\text { Reference } \\
\text { period }\end{array}$ & $\begin{array}{l}\text { Observation } \\
\text { period }\end{array}$ & $\begin{array}{l}p \\
\text { value }\end{array}$ \\
\hline Non-surgical management per 1 million insurance holders & $10.4 \pm 1.3$ & $8.7 \pm 2.1$ & n.s. \\
Appendectomies per 1 million insurance holders & $106 \pm 8$ & $92 \pm 7$ & 0.0077 \\
Surgical therapy in \% & $91.0 \% \pm 0.9$ & $91.5 \% \pm 1.3$ & n.s. \\
$\begin{array}{l}\text { Laparoscopic appendectomy per 1 million insurance holders } \\
\text { Open or converted appendectomy per 1 million insurance }\end{array}$ & $94 \pm 7$ & $82 \pm 7$ & 0.01 \\
$\quad \begin{array}{l}\text { holders } \\
\text { Additional bowel resection per 1 million insurance holders }\end{array}$ & $6.4 \pm 0.5$ & $6.4 \pm 0.7$ & 0.027 \\
\hline
\end{tabular}

published "CODA collaborative" claimed antibiotics are non-inferior to appendectomy [18]. Appendectomy seems to be the definite therapeutic option with no chance of recurrence. On the other hand, is it more invasive than antibiotic therapy [19]. Hospital stay tends to be longer in the antibiotic therapy group, and approximately $30 \%$ of patients treated with antibiotics were in need of appendectomy within 1 year $[3,18,19]$. Another important aspect to consider are appendiceal malignancies that are coincidentally found in $0.7-2.5 \%$ of histopathological evaluation of appendectomy specimens [22-24]. Treating patients with antibiotics can delay the diagnosis and lead to incurable cancer stages.

In March 2020, $4.8 \%$ of patients with appendicitis had simultaneous COVID-19 infection and showed a higher rate of $\mathrm{CA}$. Besides a number of case reports describing patients with AA and COVID-19, detailed data is still missing [25-27]. A recently published systematic review of guidelines and recommendations for surgery during the COVID-19 pandemic advised to treat appendicitis conservatively if possible. Abscess should be treated with percutaneous drainage, and perforated appendicitis is recommended to be managed using an open approach [28]. On the basis of insurance claims data, it is not possible to make a statement about severity or symptoms of the COVID-19 infection. Furthermore, we do not know whether patients/surgeons were aware of the infection in time of surgery.

High priority in Germany during the COVID-19 pandemic in early 2020 was the maintenance of medical care for COVID patients but even so non-COVID patients and to prevent a breakdown of the health system, as seen in other European countries [14, 29]. By postponing nonurgent procedures, Germany managed to get through the pandemic, without overwhelming hospital capacities and still offering high-quality health care for the population [14]. Thus, no overall change in the treatment regime of acute appendicitis was visible in Germany.

This analysis has some limitations. First of all, BARMER insurance holders are not balanced by gender or age to the entire German population. Furthermore, analyzing data from one single insurance company might be a selection bias.

Provided data was collected by assessing diagnoses and procedure codes of inpatients. Thus, diagnoses were not verified by histopathological findings, and the coding of localized versus generalized peritonitis cannot be validated by the operative finding. There is no more information available about the COVID-19 infections in this data analysis. This leads to a great uncertainty whether patients were asymptomatic or did have a severe infection.

Another uncertainty is the conservative treatment of patients for suggested appendicitis. Due to the missing pathological specimen and medical records, e.g., as results of CT-scan or appendicitis scores, there is no prove for the suggested diagnosis; therefore, patients might be included in this data set with no appendicitis or another disease.

Furthermore, we did not include data of outpatient treatment, as we performed the analysis based on procedure codes. This leaves a great uncertainty regarding our proposition that patients with uncomplicated appendicitis and presumably mild symptoms were treated ambulatory.
Table 5 Complications of appendicitis treatment in \% and median length of stay during reference and observation period

\begin{tabular}{llll}
\hline & Reference period & Observation period & $p$ value \\
\hline Median length of stay in days (only appendectomy) & 4 & 3 & n.s. \\
Re-admission within 30 days & $6.8 \% \pm 0.81$ & $5.8 \% \pm 0.61$ & 0.05 \\
Anastomosis leakage or appendix stump leakage & $0.41 \% \pm 0.2$ & $0.42 \% \pm 0.17$ & n.s. \\
Wound infection & $1.3 \% \pm 0.4 \%$ & $1.1 \% \pm 0.4$ & n.s. \\
Re-operation & $0.84 \% \pm 0.35$ & $0.83 \pm 0.32$ & n.s. \\
Peritonitis or sepsis & $2.9 \% \pm 0.5$ & $2.6 \% \pm 0.3$ & n.s. \\
\hline
\end{tabular}




\section{Conclusion}

This study shows a significant reduction in overall patients with acute appendicitis during the COVID-19 pandemic in spring 2020 in Germany. Rates of patients with UA dropped significantly, while CA was not affected. One hundred four patients during observation period were simultaneously infected with COVID-19, but no difference was seen regarding their treatment. Nevertheless, there was no difference in treatment or complication rate. This study supports the hypothesis that uncomplicated appendicitis is no progressive disease to complicated appendicitis.

Authors' contributions Study conception and design: SF, CTG, UM, and AW. Acquisition of data: FK, LA, HL, UM, and AW. Analysis and interpretation of data: FK, LA AvdB, CK, SM, JD, JFL, HL, and AW. Drafting of manuscript: FK, LA, AvdB, CK, SM, JFL, UM, and AW. Critical revision of manuscript: all authors.

\section{Compliance with ethical standards}

Conflict of interest The authors declare that they have no conflict of interest.

Ethical approval This article does not contain any studies with human participants or animals performed by any of the authors.

Ethical statement Insurance companies are eligible to perform data analysis of anonymized insurance holder data by the social security statutes (SGB V). Therefore, no ethical statement was needed.

\section{References}

1. Snyder MJ, Guthrie M, Cagle S (2018) Acute appendicitis: efficient diagnosis and management. Am Fam Physician 98(1):25-33

2. Bhangu A, Søreide K, Di Saverio S, Assarsson JH, Drake FT (2015) Acute appendicitis: modern understanding of pathogenesis, diagnosis, and management. Lancet. 386(10000):1278-1287

3. Jaschinski T, Mosch CG, Eikermann M, Neugebauer EAM, Sauerland S (2018) Laparoscopic versus open surgery for suspected appendicitis. Cochrane Database Syst Rev 2018(11)

4. Ergul E (2007) Heredity and familial tendency of acute appendicitis. Scand J Surg 96(4):290-292

5. Sadr Azodi O, Andrén-Sandberg Å, Larsson H (2009) Genetic and environmental influences on the risk of acute appendicitis in twins. Br J Surg 96(11):1336-1340

6. Humes D, Simpson J (2006) Clinical review acute appendicitis. Bmj. 333:530-534

7. Farahbakhsh F, Torabi M, Mirzaee M (2020) A comparative study on the diagnostic validity of three scoring systems in the diagnosis of acute appendicitis in emergency centres. African J Emerg Med 10(3):132-135

8. Marin D, Ho LM, Barnhart H, Neville AM, White RR, Paulson EK (2010) Percutaneous abscess drainage in patients with perforated acute appendicitis: effectiveness, safety, and prediction of outcome. Am J Roentgenol 194(2):422-429

9. Guan W, Ni Z, Hu Y, Liang W, Ou C, He J, Liu L, Shan H, Lei CL, Hui DSC, du B, Li LJ, Zeng G, Yuen KY, Chen RC, Tang CL, Wang T, Chen PY, Xiang J, Li SY, Wang JL, Liang ZJ, Peng YX,
Wei L, Liu Y, Hu YH, Peng P, Wang JM, Liu JY, Chen Z, Li G, Zheng ZJ, Qiu SQ, Luo J, Ye CJ, Zhu SY, Zhong NS, China Medical Treatment Expert Group for Covid-19 (2020) Clinical characteristics of coronavirus disease 2019 in China. N Engl J Med 382(18): 1708-1720

10. Sohrabi C, Alsafi Z, Neill NO, Khan M, Kerwan A (2020) World Health Organization declares global emergency: a review of the 2019 novel coronavirus (COVID-19). Int J Surg 76:71-76

11. Li X, Xu Z, Wang T, Xu X, Li H, Sun Q et al (2020) Clinical laboratory characteristics of severe patients with coronavirus disease 2019 (COVID-19): a systematic review and meta-analysis Xiang. Clin Epidemiol Glob Health

12. Robert Koch Institut (2020) [Internet] [cited 2020 Sep 26]. https:// experience.arcgis.com/experience/478220a4c454480e823b17327b2bfld4

13. Bundesminesterium für Gesundheit: [Internet] [cited 2020 Sep 26]. https://www.bundesgesundheitsministerium.de/coronavirus/ chronik-coronavirus.html

14. Flemming S, Hankir M, Ernestus RI, Seyfried F, Germer CT, Meybohm P, Wurmb T, Vogel U, Wiegering A (2020) Surgery in times of COVID-19 - recommendations for hospital and patient management. Langenbeck's Arch Surg 405(3):359-364

15. Sahm M, Koch A, Schmidt U, Wolff S, Pross M, Gastinger I, Lippert H (2013) Akute Appendizitis - Klinische Versorgungsforschung zur aktuellen chirurgischen Therapie. Zentralbl Chir 138(3):270-277

16. Slagman A, Behringer W, Greiner F, Klein M, Weismann D, Erdmann B et al (2020) Medizinische Notfälle während der COVID-19-Pandemie. Dtsch Arztebl Int 117(34-34):545-552

17. Baum P, Diers J, Lichthardt S, Kastner C, Schlegel N, Germer CT, Wiegering A (2019) Originalarbeit Sterblichkeit und Komplikationen nach viszeralchirurgischen Operationen. Dtsch Arztebl Int 116(44):739-746

18. The Coda Collaborative (2020) A randomized trial comparing antibiotics with appendectomy for appendicitis. N Engl J Med [Internet] NEJMoa2014320

19. Harnoss JC, Zelienka I, Probst P, Grummich K, Müller-Lantzsch C, Harnoss JM, Ulrich A, Büchler MW, Diener MK (2017) Antibiotics versus surgical therapy for uncomplicated appendicitis: systematic review and meta-analysis of controlled trials (PROSPERO 2015:CRD42015016882). Ann Surg 265(5):889900

20. Poillucci G, Mortola L, Podda M, Di Saverio S, Casula L, Gerardi C et al (2017) Laparoscopic appendectomy vs antibiotic therapy for acute appendicitis: a propensity score-matched analysis from a multicenter cohort study. Updat Surg 69(4):531-540

21. Styrud J, Eriksson S, Nilsson I, Ahlberg G, Haapaniemi S, Neovius G, Rex L, Badume I, Granström L (2006) Appendectomy versus antibiotic treatment in acute appendicitis. A prospective multicenter randomized controlled trial. World J Surg 30(6):1033-1037

22. Loftus TJ, Raymond SL, Sarosi GA Jr, Croft A, Smith RS, Efron PA et al (2017) Predicting appendiceal tumors among patients with appendicitis. J Trauma Acute Care Surg 82(4):771-775

23. Smeenk RM, van Velthuysen MLF, Verwaal VJ, Zoetmulder FAN (2008) Appendiceal neoplasms and pseudomyxoma peritonei: a population based study. Eur J Surg Oncol 34(2):196-201

24. Kangaspunta H, Tahkola K, Wirta EV, Kotaluoto S, Laukkarinen J, Ukkonen M (2020) Preoperative computed tomography is poor in detecting tumors of the appendix among patients with acute appendicitis: a cohort study of 5,224 appendectomies. J Trauma Acute Care Surg 88(3):396-401

25. Oh D, Min Y, Yong J, Jun W (2020) What surgeons should know about emergency operation for COVID-19 confirmed patients: a case report. Int J Surg Case Rep 77:503-506

26. Abdalhadi A, Alkhatib M, Mismar AY, Awouda W, Albarqouni L (2020) Can COVID 19 present like appendicitis? IDCases [Internet] 21:e00860 
27. Alsuwailem AB, Turkistani R, Alomari M (2020) Complicated appendicitis in a pediatric patient with COVID-19: a case report. Cureus 12(6)

28. Moletta L, Pierobon ES, Capovilla G, Costantini M, Salvador R, Merigliano S, Valmasoni M (2020) International guidelines and recommendations for surgery during Covid-19 pandemic: a systematic review. Int J Surg 79:180-188
29. Prante FJ, Bramucci A, Truger A (2020) Decades of tight fiscal policy have left the health care system in Italy ill-prepared to fight the COVID-19 outbreak. Intereconomics. 55(3):147-152

Publisher's note Springer Nature remains neutral with regard to jurisdictional claims in published maps and institutional affiliations. 